\title{
New section: surveys, surveillance, and health promotion in Eastern Europe
}

\author{
Prof. Morabia and Abel are editors-in-chief of this journal
}

Why? Where? What? Good questions!

Let us start with the why? Lately, SPM has been receiving an increasing number of very interesting papers emanating from research groups in countries such as Poland, Russia, Hungary, Georgia, Ukraine, and Armenia. These countries either belonged to the former USSR or had socialist economies until a few years ago. Very little was known about the evolution of public health in this area of the world. Intrigued, we decided to make a call for papers. This initiative was heard and successful, proving that researchers in Eastern Europe are looking for places to publish surveillance and health promotion data. However, we also realized that the historical separation between East and West has had important consequences on the mode of producing scientific papers. These papers required specific attention from the editors, on the one hand not to reject them outright solely on the basis of their appearance, and on the other to adapt their presentation to the usual standards of publications in SPM. Hence, this initiative of having a separate section on Eastern European papers. These papers will undergo special treatment. We may sometimes have to work with the authors on the format of their manuscript, including tables and figures, and sometimes, as we did in the past, propose an external expert to repeat some of the analyses.

Where? That's right. Where is Eastern Europe? The European region of the WHO comprises about 850 million people. If Woodie Guthrie were European he might have sung that the European region went from the Atlantic to the Pacific Ocean, from Siberia to the northern border of Iran and China, and from the Arctic Ocean to the Mediterranean Sea. WHO distinguishes two groups of countries that represent Eastern Europe. The new independent states, that is, the 13 countries that formerly belonged to the USSR: Armenia,
Azerbaijan, Belarus, Georgia, Kazakhstan, Kyrgyzstan, Moldova, Russia, Tajikistan, Turkmenistan, Ukraine, Uzbekistan, plus the three Baltic Republics (Estonia, Latvia, Lithuania); and the Countries of Central and Oriental Europe, that is, the 12 countries that used to belong to the influence zone of the USSR without being part of it, and/or had planified economies: Albania, Bosnia/Herzegovina, Bulgaria, Croatia, Czech Republic, Hungary, Macedonia, Poland, Romania, Serbia/Montenegro, Slovakia (Slovak Republic), and Slovenia. This definition of Eastern Europe is very much determined by the historical impact of the Russian Revolution and the Yalta Conference after World War II. We do however believe that it is relevant for the purpose of the section because it defines a set of countries and research communities that have undergone a relatively homogeneous development in the basic sciences of public health (e.g., epidemiology, sociology, biostatistics), but a development that was essentially independent from that of the rest of the world. This historical, political, and economical schism imposes specific constraints on our editorial activity to build the necessary interface. This historical watershed is bound to disappear. SPM's new section can be viewed as a temporary bridge to accelerate the reunification of public health researchers.

What type of research are we hoping to receive for this section? The first two publications in the new series are examples of the type of research papers we hope that SPM will be receiving in the future. Schmid et al. (2004) describe the methodological issues related to the development of the first telephone-based health survey in Moscow. This was a collaborative project between the Russian Center for Preventive Medicine in Moscow and the Center for Disease Control in Atlanta. Mikiel-Kostyra et al. (2004) report the results of 
a survey, involving 11422 newborns and 10156 infants under six months, on the factors affecting exclusive breastfeeding in Poland.
We hope this new section will contribute to bringing the Europe's East more into the forefront of mainstream public health research.

Alfredo Morabia and Thomas Abel

\section{References}

Mikiel-Kostyra M, Mazur J, Wojdan-Godek E (2005). Factors affecting exclusive breastfeeding in Poland: cross-sectional survey of populationbased samples. Soz Praventiv Med 50: 52-9.
Schmid T, Zabina H, McQueen D, Glasunov I, Potemkina $R$ (2005). The first telephone-based health survey in Moscow: building a model for behavioral risk factor surveillance in Russia. Soz Praventiv Med 50: 60-2.
Address for correspondence

Prof. Dr. Alfredo Morabia

Hôpital Cantonal Universitaire Division d'épidémiologie clinique 25, rue Micheli-du-Crest CH-1205 Genève

e-mail: A.Morabia@hcuge.ch 